\title{
The Role of Ki-67 In Predicting Prognosis And Overall Survival In Pediatric Gastrointestinal Lymphoma
}

\author{
Dr.S.Selvi ${ }^{1}$, Dr. M. Satish Devakumar ${ }^{2}$, Dr.T.Chitra ${ }^{3}$ \\ I(Department Of Pathology, Madras Medical College,The Tamilnadu Dr.MGR Medical University,India) \\ ${ }_{2}^{2}$ (Department Of Surgical Gastroenterology, Kilpauk Medical College,Chennai,The Tamilnadu Dr.MGR \\ Medical University,India) \\ ${ }^{3}$ (Department Of Pathology, Institute Of Child Health, Egmore, The Tamilnadu Dr. MGR Medical University, \\ India)
}

\begin{abstract}
:
Background: The variable prognosis of gastrointestinal lymphoma within a pathological stage necessitates the identification of subgroups of patients with a more aggressive disease.

Aims and Objectives: The aim of the present study was to identify the incidence and distribution of paediatric lymphomas, to assess conventional morphological prognostic parameters among the various histopathological subtypes by immunophenotyping and to evaluate the expression of Ki67 in GI lymphoma and correlate with several clinico-pathological features and prognosis.

Materials and methods: Formalin-fixed paraffin-embedded tissue samples from 30 paediatric cases treated by surgical resection for gastrointestinal lymphoma in the year 2008 to 2014 were studied by immunohistochemistry, using monoclonal antibodies to Ki67,CD3,CD20 and CD45.

Results: The results were correlated with clinico-pathological features. Higher Ki-67 labeling index correlated significantly with overall survival rate. The mean Ki-67 labeling index was higher in aggressive lymphoma such as Burkitt, Anaplastic lymphoma and Diffuse large B cell lymphoma. Ki-67 was identified as important prognostic factors.

Conclusion: In this study, $60 \%$ Ki 67 cut-off value appear to have a predict value for overall survival and help clinicians to distinguish between GI lymphoma with good and poor outcome. Follow up of these patients for 10 more years could throw more light on the role of Ki-67 LI as long term prognostic indicators.
\end{abstract}

Keywords: B Cell Type,CD20,CD45, Gastrointestinal lymphoma,Ki-67.

\section{Introduction}

Lymphomas are neoplasms of the immune system. Lymphomas are of two types, namely, Hodgkin's and Non Hodgkin's lymphoma (NHL). Malignant cells affecting the organs such as Gastrointestinal tract, brain and skin other than lymph node are referred to as extranodal lymphoma. Extranodal lymphomas are usually non Hodgkin's type commonly involving gastrointestinal tract.[1]Gastrointestinal(GI) lymphoma constitutes about $10-15 \%$ of all non Hodgkin's lymphoma and about $30-40 \%$ of all extranodal lymphoma. Malignant tumors of the gastrointestinal tract especially in pediatric age group are rare and the incidence is less than $1 \%$ of all pediatric tumors. [2] Pediatric lymphoma differs from adult lymphoma due to their differences in target cells and exposure to environmental agents. Gastrointestinal tract (GIT) is the most frequently involved by extra nodal Non-Hodgkin's lymphoma in pediatric age group. Topographically the ileocaecal region, appendix, and ascending colon are the most commonly involved[3] whereas in adults stomach is the most common site.[4]The prognosis for childhood gastrointestinal lymphoma improves with realization thatalmost all cases are disseminated at diagnosis and systemic therapy is needed for long term disease free survival.[5]

Patients with gastrointestinal lymphoma usually presents with abdominal pain, mass, vomiting, diarrhea, constipation, intestinal obstruction/intussusception and nodal involvement. A laboratory investigation includes complete blood count, peripheral smear, bone marrow aspiration study, serum Lactate Dehydrogenase (LDH), uric acid estimation and radiological examination of abdomen and pelvis.Selection of appropriate mass or node for histological material is important. Histology remains the primary means for definitive diagnosis and should be supplemented if possible with immune-phenotype and cytogenetic studies.Lymphoma has to be differentiated from other small round cell tumor showing similar monotonous population of cells such as neuroblastoma, The Ewing family of tumours, rhabdomyosarcoma, desmoplastic small-round-cell tumor. All small round tumors are difficult to diagnose by light microscopy. An accurate diagnosis of these tumors has become increasingly crucial, as desperate approaches to therapy are used for distinct tumour types. Hence IHC and molecular genetics play a major role to overcome the difficulties in diagnosis and treatment of patients.

The aim of this study is to clarify the clinicopathological features of paediatric gastrointestinal B-cell lymphoma in our institution, to correlate with outcome and finally to identify the significant prognostic factors. 


\section{Materials And Methods}

This study of Extra-nodal Gastrointestinal (GI) Lymphoma was conducted in the Institute of Child Health, Egmore, Madras Medical College, Department of Pathology, Chennai during the period between July 2008 and June 2014. All the GI lymphoma cases reported in resected specimens with age group between 1to $14 y$ ears were included for the study. Detailed history of the cases regarding age, sex, history, type of procedure, details of gross characteristics were obtained for all the 30 resected GI Lymphoma cases were recorded in the Paediatric Surgical pathology records.Hematoxylin and Eosin (H\&E) stained, 4 microns thick sections of the paraffin tissue blocks of resected specimens were reviewed.

\section{Method Of Data Collection}

The clinico-pathological parameterssuch age (1-14years), gender, tumour size $(<5$ and $>5 \mathrm{~cm})$, tumour location (Ileum, Caecum, ascending colon, liver and Spleen), macroscopic appearance were evaluated.

Age more than 14years, non-neoplastic lesions and benign tumors of GIT, lymphoma of mediastinaladenopathy, peripheral adenopathy, testicular and para-pharyngeal mass were excluded from the study.Lymphomas were classified based on St. Jude Staging. Microscopic appearances were divided into B cell and T cell type.

All the cases of GI Lymphoma diagnosed by H\&E stained section were subjected to immunohistochemistry for a panel of 4 markers - CD3,CD20,CD45 and Ki-67. The immunohistochemicallystained slides were analyzed for the presence of reaction, cellular localization, percentage of cells stained and intensity of reaction. Nuclear staining was assessed for $\mathrm{Ki}-67$. Cytoplasmic staining was assessed for T-cell, B-cell and both T \& B-cell for CD3, CD20 and CD45 respectively.

The Ki-67 labeling index (LI) was determined by counting at high power view 1000 tumour cell nuclei in areas of the section. The Ki-67 labeling index for the 30 tumours ranged from $0 \%$ to $98 \%$ with a mean labeling index of 58.4\%. Labeling index greater than $60 \%$ indicates High Ki-67. Labeling index lesser than $60 \%$ indicates Low $\mathrm{Ki}-67$.

\section{Statistical analysis:}

Data was analysedusing SSPS version 11.5 which consisted of computing the frequency counts and percentages for qualitative variables and mean for the quantitative variables. Numerical data were expressed as mean with standard deviation. Categorical variable were expressed as frequency and percentage.Survival analysis was calculated using Kaplan-Meier test and presented as cumulative survival rates. Comparison between two survival curves was done using Breslow test. A probability (P-value) less than 0.05 was considered statistically significant.

\section{Observation And Results}

In the study period of 60 months from July 2008 to June 2014, a total of 6300 specimens were received in the Institute of Child health, Egmore, Department of Pathology, Madras Medical College for histological examination. Total number of GI resected specimens received was 2834. The total numbers of nonneoplastic, benign and malignant cases were 2784,12 and 38 respectively. Thus the distribution of nonneoplastic lesions was $98.2 \%$, of benign tumors were $0.42 \%$ and of malignant tumors were $1.34 \%$ among the GI specimens. Of these, GI Lymphoma was reported in 30cases.

Pediatric GI Lymphoma had a peak incidence in the age group of 5 -9years. Twenty-one (70\%) cases of gastrointestinal lymphoma were reported in males and nine (30\%) in females. The clinical features associated with paediatric GI lymphomawere Abdominal pain (76.7\%), Abdominal swelling (70\%), Vomiting (40\%), Obstruction/Intussusception (20\%) and Constipation (16.7\%). Among the study samples, 15 cases (50\%) had tumor less than $5 \mathrm{~cm}$ in size and another 15 cases $(50 \%)$ were $5 \mathrm{~cm}$ or more in size.

\section{Topographic distribution:}

The most common location of GILymphoma was at the Ileum which constituted about $66.7 \%(\mathrm{n}=$ 20 cases) of the cases. Two (6.7\%) cases involved the Large intestine(Caecum)[Figure1], 6 (20.0\%) cases involved both (Ileocaecal region) [Figure2] and 2 (6.7\%) cases were in Spleen[Figure3].

\section{Histopathological findings :}

The distribution of various Histological subtypes in GI Lymphoma in our sample size were grouped into Burkitt's [Figure4.1] in10 cases (33.3\%), 9 cases (30.0\%) were of the Malt type [Figure5.1], 7 cases (23.3\%) were DLBCL type, 1 case $(3.3 \%)$ was anaplastic type, 1 case $(3.3 \%)$ was lymphoblastic type and 2 cases $(6.7 \%)$ belonged to splenic lymphoma.Bone marrow involvement was observed in 5 cases $(16.7 \%)$ and no bone marrow involvement in the remaining 25 cases $(83.3 \%)$. Most of the tumors (73.3\%) presented in stage IIE and 8 cases $(26.7 \%)$ belonged to stage IVE. 
Study sample of 30cases with varying type and stage were subjected to immune-histochemical (IHC) analysis with a panel of markers - CD3, CD20, and CD45.The resultsobservedwere CD20 positive [Figure4.2] for 28 cases (93.3\%), CD45 positive for 30 cases (100\%) and CD3 [Figure4.3] negative for all 30 cases, which denote Bcell type of Lymphoma [Table2].Response to Chemotherapy was noted for 25 cases (83.3\%) and no response to Chemotherapy noted in 5 cases $(16.7 \%)$. Among 30 cases, distribution of survivalrate was increased to $83.3 \%$ and death ratewas decreased to about $16.7 \%$, probably dueto early detection and treatment of tumor.

Among the 3 patients with recurrence of disease after treatment, only one is alive and is now on second line chemotherapy. There were 5 deaths in our study with 2 death due to disease recurrence, 2 due to chemotherapy complication and 1 due to sepsis.

\section{Survival Analysis}

The mean duration of follow-up was 26 months (range of 7 months to 67 months). The Overall and disease free survival rates in our study were $83.3 \%$ and $89.2 \%$ respectively (FIG $6 \& 7$ ). While calculating disease free survival those with progressive disease are non responders were not included. The correlation between the overall survival and various clinicopathological parameters had shown that no bone marrow infiltration $(\mathrm{p}<0.001)$, localised disease $(\mathrm{p}<0.001)$, early stage disease $(\mathrm{p}<0.001)$, non Burkitt type $(\mathrm{p}=$ 0.031), response to chemotherapy $(\mathrm{p}<0.001)$ and low Ki67 labelling index had statistically significantly influenced the overall survival. When the disease free survival was correlated with the same clinicopathological parameters, no bone marrow infiltration ( $p<0.001)$, localized disease ( $p<0.001)$, early stage (p 0.006) and response to chemotherapy ( $\mathrm{p}<0.001)$ were found to have significant effect on disease free survival as shown in Table 3.

The mean Ki-67 Labeling index(LI) was 58.5\% with High Ki-67 LI [Figure4.4] was seen in 56.7\% of cases and low LI [Figure5.2] in 36.7\% of cases.There was increasing percentage of cases with high Ki-67 LI with Extensive involvement, Stage IVE, BM infiltration.No significant association between Overall Survival rates with age, gender, tumour site was observed.There is significant association between Ki-67 with Overall Survival rate as shown in [Table 3].

\section{Discussion}

Malignant lymphomas are the third most common cancer in the childhood. The distinction between non-Hodgkin's lymphoma of adults and those of children is important because children usually present with diffuse extra-nodal disease when compared with adults, in whom the primary nodal disease is more common [6].Primary Gastrointestinal [GI] malignancies are the commonest extra-nodal site of involvement in children. Nevertheless, primary GI lymphomas are rare in children and represent less than $5 \%$ of all pediatric population with very limited data available in Indian population. [7]

Many biological markers have been examined as potential tools for the evaluation of the biological behavior of gastrointestinal lymphoma in order to predict its clinical outcome. Among these, immunohistochemical staining of proliferation marker $\mathrm{Ki}-67$ has been proposed to be of prognostic value. In the present study, immuno-histochemical evaluation was done in 30 cases of gastrointestinal Lymphoma and an attempt was made to correlate the Ki-67 labeling index with the known prognostic factors of GI Lymphoma

The peak age incidence of GI lymphoma has been reported in 5 to 15 years age group in the literature $[6,7]$. In the present study, mean age of pediatric GI lymphoma was 6.10 years (Standard deviation \pm 2.482 ). In the study done byMorsi et al,[8] the incidence of GI Lymphoma in male and female was $75.7 \%$ and $24.3 \%$ respectively. In concurrence with the above study, a significant male predominance (76\%) of GI Lymphoma was noted with female patients being accounted for $24 \%$ of cases.

The most common site of pediatric GI Lymphoma in present study is the small bowel (85\%), followed by ileo-caecal region $(20 \%)$, large intestine $(6.7 \%)$ and spleen $(6.7 \%)$. This is almost similar to the most of the reported series in the literature.[8, 9, 10]

Abdominal pain was the most common presentation $(76.7 \%)$ in the present studyfollowed by abdominal swelling (70\%), vomiting (40\%), intestinal obstruction (20\%) and constipation (16.7\%). In contrast to most of other studies, none of our patients presented with generalized lymphadenopathy. Bone marrow aspiration was done in all cases, which revealed bone marrow infiltration in only 5 cases $(16.7 \%)$. The incidence of bone marrow infiltration was slightly higher in the present study when compared to other studies, which range from 3.5 to $9.1 \%$.[10]

All the patients in the study group underwent complete surgical removal of the diseased segment of bowel or organ. The ideal treatment approach in GI Lymphoma remains controversial. Radical tumor resection followed by chemotherapy in early disease, and limited or no resection followed by poly-chemotherapy in advanced disease may be the justified approach. However recent studies done by Rainaet al 2006, have proposed the use of chemotherapy alone as an effective treatment option in primary GI lymphoma in all stages.[11] 
The examination of resected specimen in the study group revealed Burkitt lymphoma (33\%), MALToma, DLBCL, Anaplastic lymphoma, Lymphoblastic lymphoma and Hodgkins. The incidence of various pathological subtypes in our study was comparable to the study by Morsi et al.

Ranjanbandyopadhyay et al has showed that there was 50\% distal small bowel involvement shown in [Table 4] except one case all were males and presented with intestinal obstruction in half of cases. All cases had intestinal growth with $50 \%$ shows regional involvement. This is consistent with the current study with male predominance, small bowel involvement with regional lymph node.

With cut-off value of $60 \%$, we found that $\mathrm{Ki} 67$ has statistically significant impact on overall survival in patients with pediatric GI lymphoma. However, high Ki-67 value, which was associated with poorer overall survival in the study, has not shown any significance in predicting disease free survival.

Cell proliferation rate is a vital parameter in grading neoplasm and predicting clinical outcome. In our study, Burkitt lymphoma showed highest $\mathrm{Ki} 67$ positivity ranging between $80-98 \%$, followed by lymphoblastic lymphoma (92\%), anaplastic lymphoma (80\%), DLBCL (40-80\%) and MALToma (10-50\%). The present study clearly demonstrates that $\mathrm{Ki}-67$ may add both diagnostic and prognostic value in pediatric GI lymphoma.

Ann Arbor classification or its modification by Musshoff was applied by most author to describe the extent of disease. In our study we applied St. Jude satging system to describe the extent of disease. Most of our patients belonged to stage II disease with disease free survival of $88 \%$ when compared to advanced (stage IV E) disease with disease free survival of 37.5\%. In a similar study by Patte $\mathrm{C}$ et al, 2001, showed that patients with Stage II has disease free survival of about 98 to $100 \%$ versus $76 \%$ in those with most extensive disease. Most other publications have stated an survival rate ranging from 24 to $87 \%$ for intestinal lymphoma, which was $83.3 \%$ in our series and $80.6 \%$ in other prospective study by Ahmed et al. In view of diverging definitions, various staging classification, small cohort of patients and different histological definition in most publication, it is difficult to have a more detailed analysis concerning stage and histological subtypes.

The survival analysis in the present study (figure $6 \& 7$ ) has shown that bone marrow infiltration, extensive disease, Burkitt's type, advanced stage of disease, non responders to chemotherapy and high Ki 67 values were significantly associated with poorer overall survival. This fact matches with other studies showing that the outcome depends more on the tumor burden at diagnosis [12] and can be predicted by high Ki 67 value, Serum LDH, interleukin-2, B-2 microglobulin levels. [10]

Bone marrow infiltration, extensive disease, Burkitt's type, advanced stage of disease and nonresponders to chemotherapy were in addition found to significantly influence the disease free survival. This is consistent with earlier reports, [13,14] demonstrating that disease free survival is influenced by the extent of disease at the initiation of therapy.

Raina $\mathrm{V}$ et al in the study sample of 77 new cases of primary gastrointestinal lymphoma over the period of 15 years have found that gastrointestinal tract is the most common extranodal site and the treatment modality in his studies demonstrates that chemotherapy alone has emerged as an effective option despite surgical resection and conclude organ preservation strategy using chemotherapy alone which can be successfully employed in a significant number of patients with primary Non Hodgkins Lymphoma.

Assigning patients to appropriate therapy depending upon their risk stratification has become the rule with different protocols. A patient with localised disease requires less intensive therapy than those with extensive disease. It is therefore necessary that patient should not be over-treated. Pediatric GI lymphoma patients in whom complete resection has been done require only few course of chemotherapy without compromising final outcome. On the contrary, patients with high risk groups (those with advanced or extensive disease) required intensive therapy with multiple drugs to achieve similar outcome in the present study.

To conclude, we noticed a higher prevalence of Burkitt's among primary paediatric GI Lymphomas and prognosis can be interpreted by using Ki 67 proliferative index. Hence, Ki-67 labelling index could be helpful for clinicians to recognise patients with high risk for recurrence and poor survival in combination with other prognostic factors like bone marrow infiltration, histological type, stage and response to chemotherapy.

\section{Conclusion}

The incidence of paediatric GI lymphoma was lower $(0.48 \%)$ in the present study when compared to western population (1.2\%). The mean age of presentation was 6.1 year with male predominance.Different types of lymphoma are associated with significantly different Ki-67 values. In this study, a $60 \% \mathrm{Ki} 67$ cut-off value appear to have a predict value for overall survival and can help thus clinicians to distinguish between GI lymphoma with good and poor outcome.Stage is the most significant prognostic factor and localised disease is associated with better survival. In conclusion the role of Ki-67 in growth and aggressiveness of GI lymphoma is complex and poorly understood. Ki-67 labelling index could be helpful for clinicians to recognise patients with high risk for recurrence and poor survival in combination with other prognostic factors like bone marrow infiltration, histological type, stage and response to chemotherapy. 
However, a large sample size and follow-up of this subset of patients for 10 or more years could help to identify the role of Ki-67 and other factors as long-term prognostic indicators in patients with GI lymphoma.

\section{References}

[1]. Aisenberg AC. Coherent view of Non- Hodgkin's lymphoma. J Clin Oncology.1995, 13:2656-75.

[2]. Kliegman R. Epidemiology of Childhood and Adolescent Cancer. In: Nelson Textbook of Pediatrics. $18^{\text {th }}$ ed. Philadelphia, PA: WB Saunders; 2007:491

[3]. Primary Gastrointestinal Malignancies in Childhood and Adolescence - an Asian Perspective Amna Khurshed, Rashida Ahmed, Yasmin Bhurgri. Asian Pacific journal of cancer prevention: 8(4):613-7.

[4]. Radman I, Jasminka K, Ayrer I. Surgical resection in the treatment of primary gastrointestinal NHL, Retrospective Study. Croat Med J. 2002, 43:555- 560.

[5]. LaQuaglia M, Stolar C, Krailo M. The role of surgery in abdominal NHL: Experience from the Children Cancer Study Group. Journal of Pediatric Surgery.1992, Vol 27, No 2: 230-235.

[6]. Murphy SB. Classification,staging, and end results of treatment of childhood Non Hodgkin's lymphomas: Dissimilarities from lymphoma in adults. Semin oncol 1980;7:332-9.

[7]. Kurshed A, Ahmed R, Bhurgri Y. Primary GI malignancies in childhood and adolescence: An asian perspective. Asian Pac J Cancer Prev 2007;8:613-7.

[8]. Parkin DM, Karmarova E, Draper GI, editors. Inter-national incidence of childhood cancer. Vol. II. IARC Scientific Publications. 1998, No. 144, IARC Mongr Eval Carcinog Man

[9]. Ranjan Bandyopathyay, sinha SK, chatterjee U,Nag D,Mukhopadhyay S,Chowdhury, SR et al.Primary pediatric GI lymphoma, Indian Journal pediatr onco 2011;32:92.5

[10]. Morsi A,Abd El-Ghani Ael-G, El- Shafiey m, Ismail H,Monir M. Clinicopathological features and outcome of management of pediatric GI lymphoma. J Egypt Natl canc Inst 2005;17:251-9.

[11]. Raina V, Sharma A, Vora A, ShuklaNK, DeoSV,DawarR. Primary GI lymphoma chemotherapy alone an effective treatment modality: Experience from a single center in india. Indian J Cancer 2006;43:30-5.

[12]. Ioachim HL: IOACHIM's Lymph Node Pathology. Philadelphia: Lippincott Williams \& Wilkins; 2009.

[13]. Bethel CA, Bhattacharyya N, Hutchinson C. Alimen-tary tract malignancies in children. J Pediat Surg.1997, 32 (7): $1004-1009$.

[14]. Shad A. Complications in the management of non-Hodgkin's lymphoma. In: Magath IT, (ed). The non-Hodgkin's lymphoma, (2nd ed.). London: Edward Arnold. 1997, 597-629.
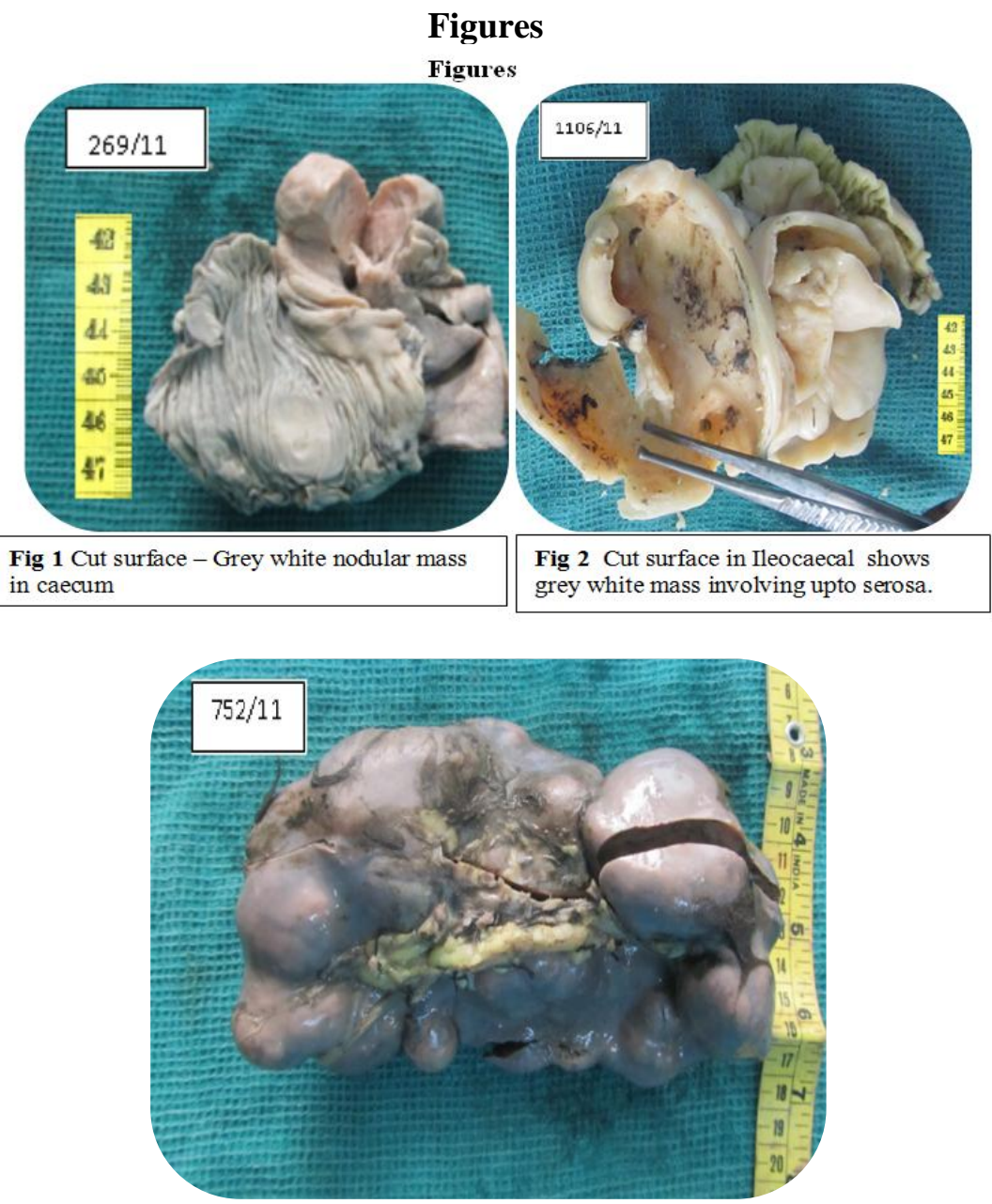

FIG 3 External surface of Spleen - nodular 


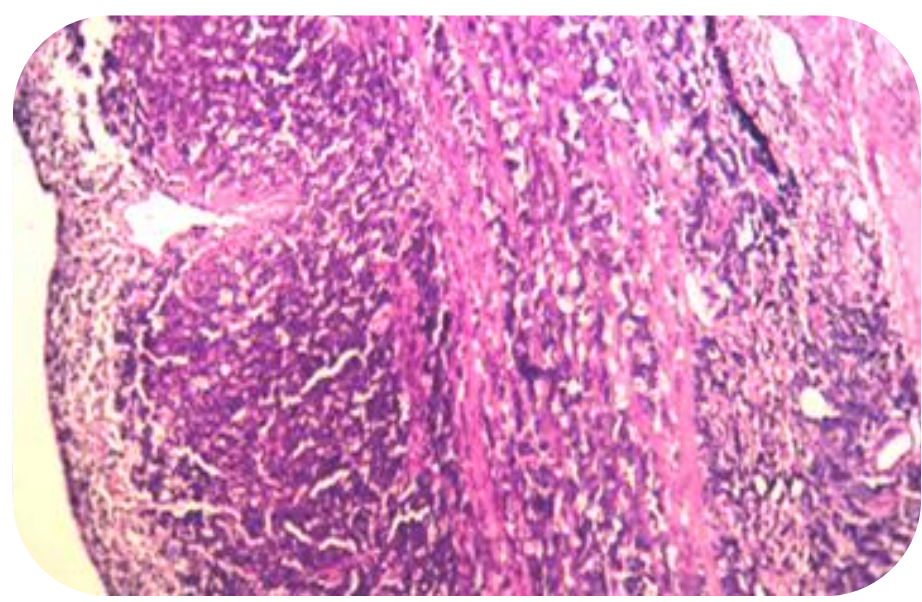

FIG 4.1 H\&E X10 Burkitt Lymphoma involving upto serosa

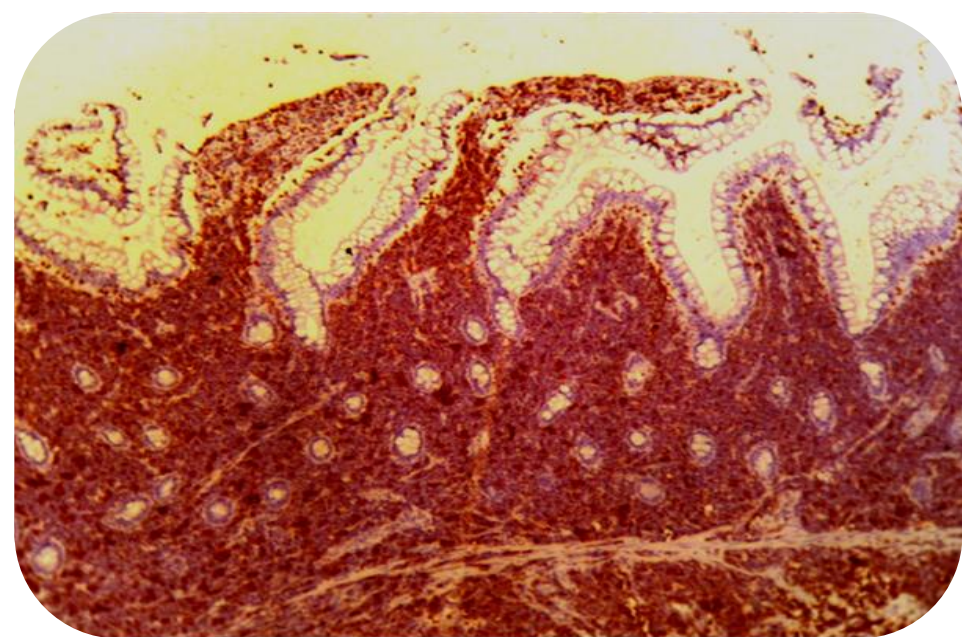

FIG 4.2: IHC X10 Burkitt Lymphoma CD 20 shows intense strong positivity.

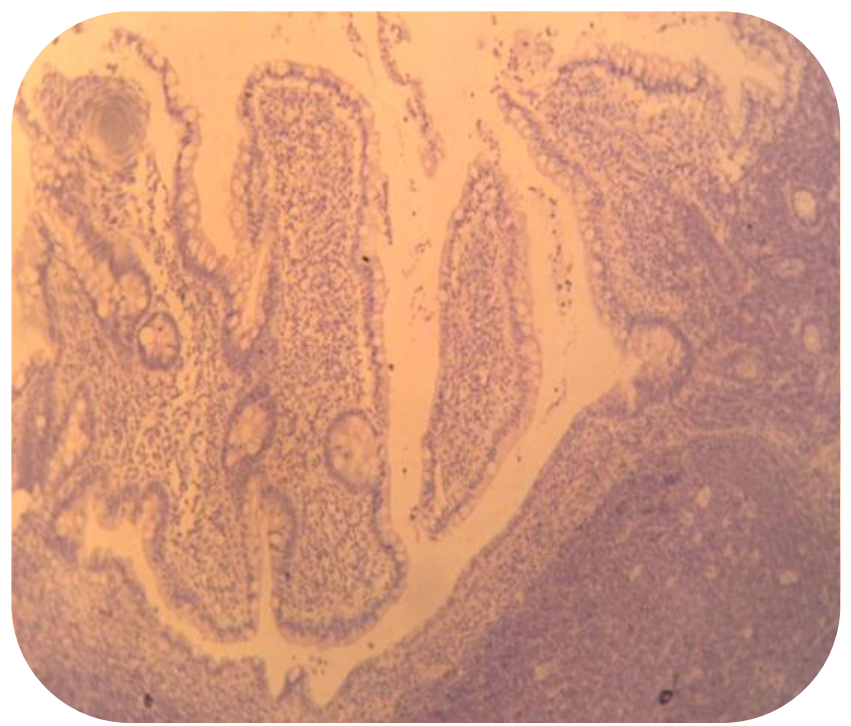

FIG 4.3: IHC X10 Burkitt Lymphoma CD3 shows negativity 


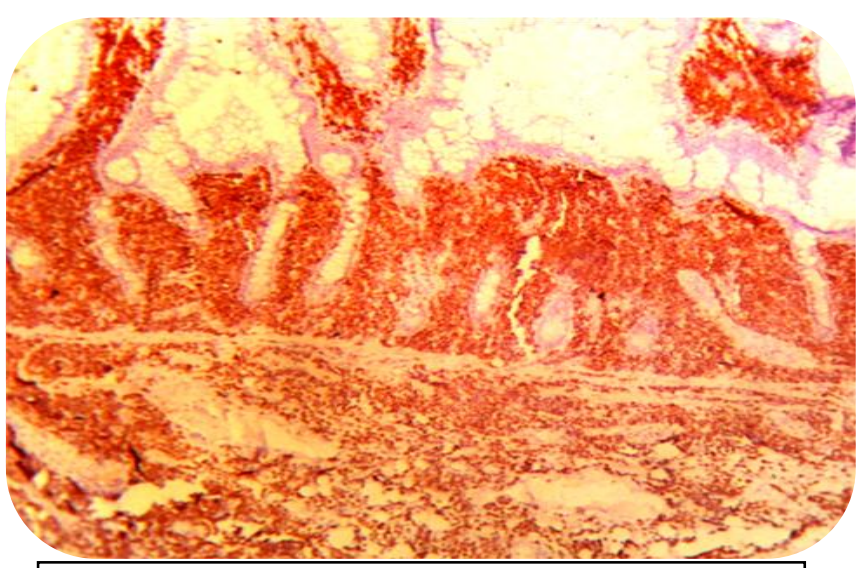

FIG 4.4 IHC X10 Ki67 Burkitt Lymphoma tumour cells show high labeling index

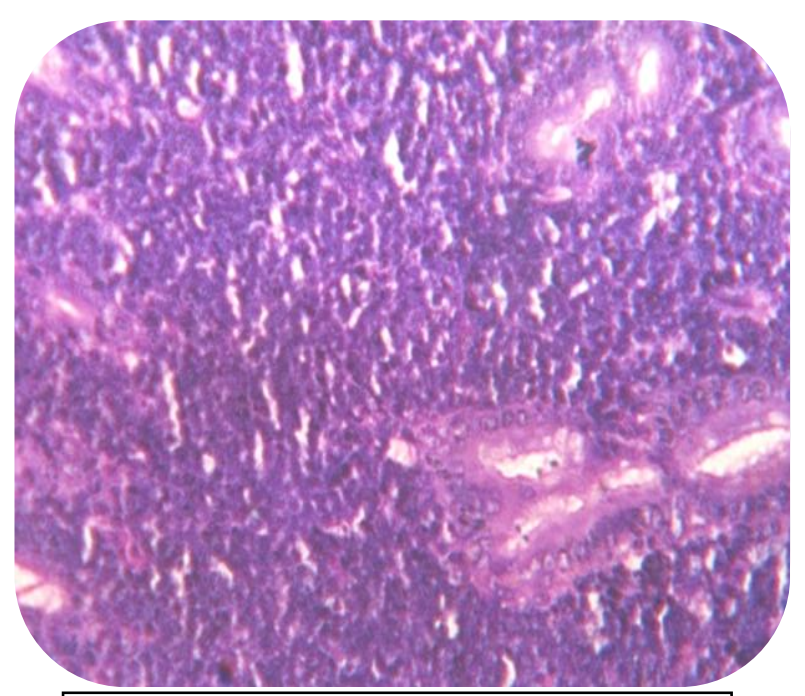

FIG 5.1 H\&E X40 Maltoma tumour cell showing lymphoepithelial invasion

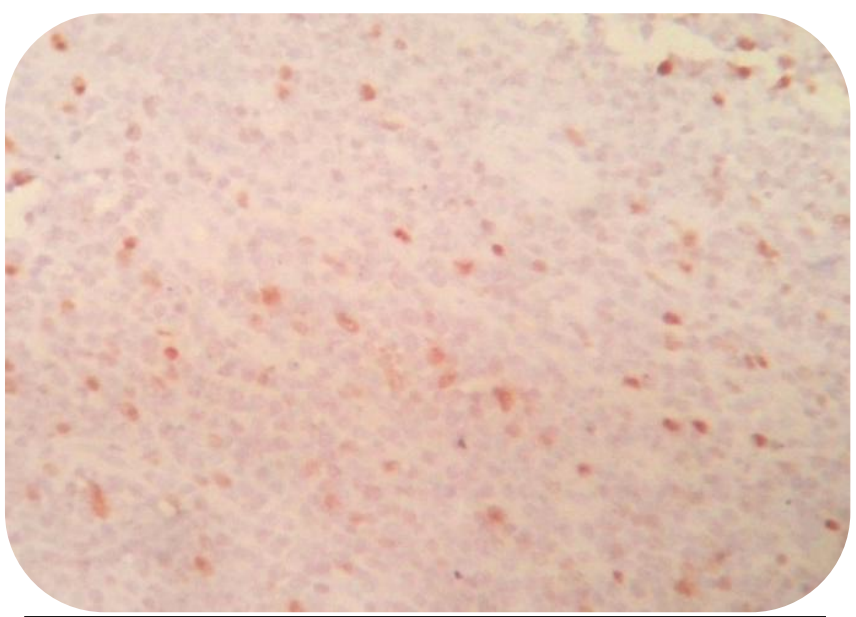

FIG 5.2: IHC X40 Maltoma -Ki67 low labeling index positive

Fig -6: Overall- Survival function 


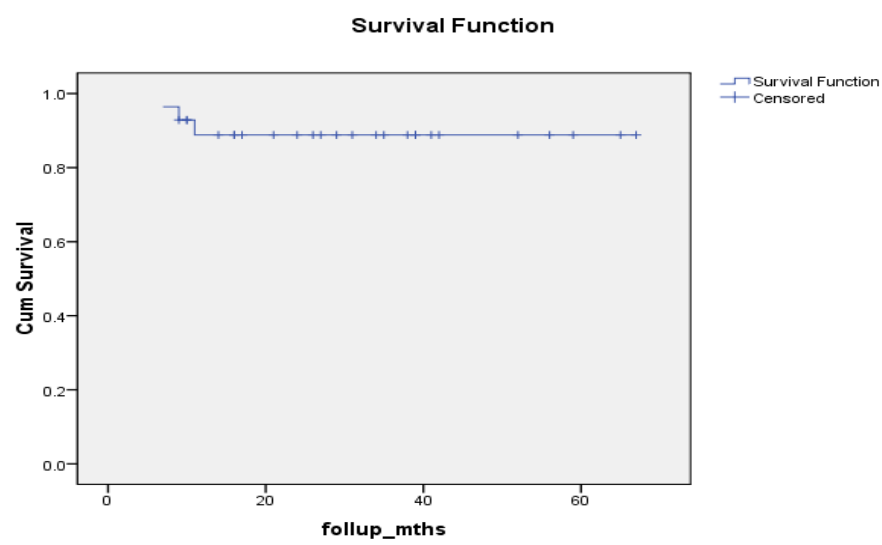

Fig 7: Survival function children excludingchemotherapycomplications

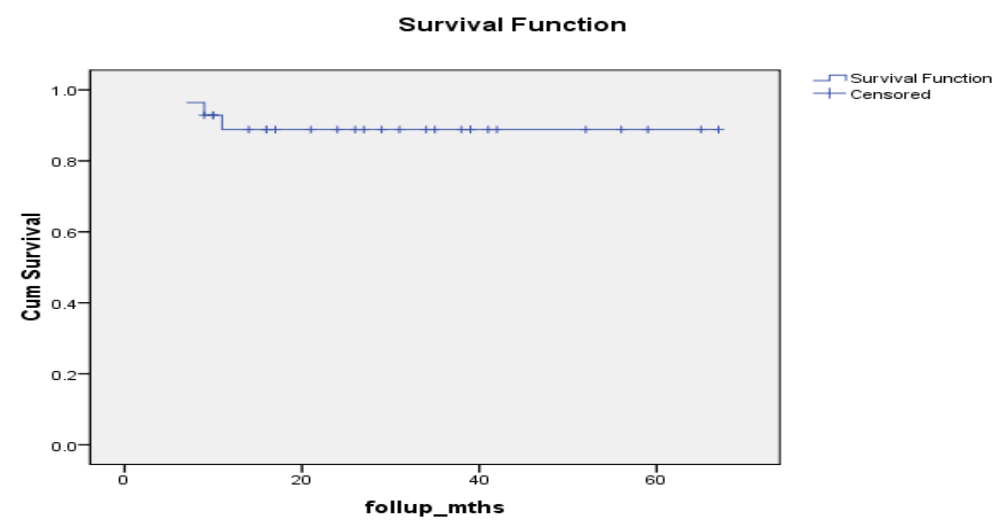

Tables

Table 1: Showing distribution of gastro intestinal lymphoma among the various clinicopathological groups for the ihc study (30 cases)

\begin{tabular}{|c|c|c|}
\hline \multicolumn{2}{|c|}{ Clinicopathological factors } & No. of cases \\
\hline Age & $\begin{array}{l}<5 \mathrm{yrs} \\
>5 \mathrm{yrs}\end{array}$ & $\begin{array}{l}15(50.0 \%) \\
15(50.0 \%)\end{array}$ \\
\hline Gender & $\begin{array}{l}\text { Male } \\
\text { Female }\end{array}$ & $\begin{array}{l}21(70.0 \%) \\
9(30.0 \%)\end{array}$ \\
\hline Tumor site & $\begin{array}{l}\text { Small intestine } \\
\text { Large intestine } \\
\text { Both } \\
\text { Spleen }\end{array}$ & $\begin{array}{l}20(66.7 \%) \\
2(6.7 \%) \\
6(20.0 \%) \\
2(6.7 \%)\end{array}$ \\
\hline Tumor extent & $\begin{array}{l}\text { Localised } \\
\text { Extensive }\end{array}$ & $\begin{array}{l}25(83.3 \%) \\
5(16.7 \%)\end{array}$ \\
\hline BM infiltration & $\begin{array}{l}\text { Yes } \\
\text { No }\end{array}$ & $\begin{array}{l}5(16.7 \%) \\
25(83.3 \%)\end{array}$ \\
\hline Histological type & $\begin{array}{l}\text { Burkitt } \\
\text { Others : Maltoma } \\
\quad \text { DLBCL } \\
\quad \text { Anaplastic type } \\
\text { Lymphoblastic type } \\
\text { Hodgkins lymphoma }\end{array}$ & $\begin{array}{l}10(33.3 \%) \\
9(30.0 \%) \\
7(23.3 \%) \\
1(3.3 \%) \\
1(3.3 \%) \\
2(6.7 \%) \\
\end{array}$ \\
\hline Stage & $\begin{array}{l}\text { IIE } \\
\text { IVE }\end{array}$ & $\begin{array}{l}25(83.3 \%) \\
5(16.7 \%)\end{array}$ \\
\hline Surgical resection & $\begin{array}{l}\text { Complete resection } \\
\text { Partial resection }\end{array}$ & $\begin{array}{l}30(100.0 \%) \\
0(0.0 \%)\end{array}$ \\
\hline Preconditioning CT & $\begin{array}{l}\text { Yes } \\
\text { No }\end{array}$ & $\begin{array}{l}0(0.0 \%) \\
30(100.0 \%)\end{array}$ \\
\hline Response to CT & $\begin{array}{l}\text { Yes } \\
\text { No }\end{array}$ & $\begin{array}{l}25(83.3 \%) \\
5(16.7 \%)\end{array}$ \\
\hline CT complication & $\begin{array}{l}\text { Yes } \\
\text { No }\end{array}$ & $\begin{array}{l}2(6.7 \%) \\
28(93.3 \%)\end{array}$ \\
\hline
\end{tabular}


Table 2: Results of IHC observed for 30 cases

\begin{tabular}{|l|l|l|}
\hline IHC & Postive(\%) & Negative(\%) \\
\hline CD20 & $28(93.3)$ & $2(6.7)$ \\
\hline CD45 & $30(100)$ & $0(0.0)$ \\
\hline CD3 & $0(0.0)$ & $30(100)$ \\
\hline Ki67 <60 & $21(70.0)$ & $2(6.7)$ \\
$>60$ & $17(56.7)$ & \\
\hline
\end{tabular}

Table 3: Overall and disease free survival analysis

\begin{tabular}{|c|c|c|c|c|c|c|c|c|}
\hline Variables & Total & $\begin{array}{l}\text { 60months } \\
\text { Overall } \\
\text { survival rate }\end{array}$ & $P$ value & Result & Total & $\begin{array}{l}\text { 60months } \\
\text { Overall } \\
\text { survival rate }\end{array}$ & $P$ value & Result \\
\hline All patients & 30 & 83.3 & 28 & & 28 & 89.2 & & \\
\hline $\begin{array}{l}\text { Age <5years } \\
>5 \text { years }\end{array}$ & $\begin{array}{l}15 \\
15\end{array}$ & $\begin{array}{l}86.7 \\
80.0\end{array}$ & 1.000 & NS & $\begin{array}{l}15 \\
13 \\
\end{array}$ & $\begin{array}{l}86.7 \\
92.3\end{array}$ & 1.000 & NS \\
\hline $\begin{array}{c}\text { Gender- Male } \\
\text { Female }\end{array}$ & $\begin{array}{l}21 \\
9\end{array}$ & $\begin{array}{l}76.2 \\
100.0\end{array}$ & 0.286 & NS & $\begin{array}{l}19 \\
9\end{array}$ & $\begin{array}{l}84.2 \\
100.0\end{array}$ & 0.530 & NS \\
\hline $\begin{array}{r}\text { NO BMI } \\
\text { BMI }\end{array}$ & $\begin{array}{l}25 \\
9\end{array}$ & $\begin{array}{l}100.0 \\
0.0\end{array}$ & $<0.001$ & Sig & $\begin{array}{l}25 \\
3 \\
\end{array}$ & $\begin{array}{l}100.0 \\
0.0\end{array}$ & $<0.001$ & Sig \\
\hline $\begin{array}{ll}\text { GIT } & \text { SI } \\
& \text { LI } \\
& \text { Both } \\
& \text { Spleen } \\
\end{array}$ & $\begin{array}{l}20 \\
2 \\
6 \\
2 \\
\end{array}$ & $\begin{array}{l}85.0 \\
50.0 \\
83.3 \\
100.0 \\
\end{array}$ & 0.564 & NS & $\begin{array}{l}19 \\
1 \\
6 \\
2 \\
\end{array}$ & $\begin{array}{l}89.5 \\
100.0 \\
83.3 \\
100.0 \\
\end{array}$ & 0.900 & NS \\
\hline $\begin{array}{r}\text { Disease Local } \\
\text { Extent }\end{array}$ & $\begin{array}{l}25 \\
5 \\
\end{array}$ & $\begin{array}{l}100.0 \\
0.0 \\
\end{array}$ & $<0.001$ & Sig & $\begin{array}{l}25 \\
3 \\
\end{array}$ & $\begin{array}{l}100.0 \\
0.0 \\
\end{array}$ & $<0.001$ & Sig \\
\hline $\begin{array}{c}\text { Histotype: Burkitt } \\
\text { Others }\end{array}$ & $\begin{array}{l}10 \\
20 \\
\end{array}$ & $\begin{array}{l}60.0 \\
95.0 \\
\end{array}$ & 0.031 & Sig & $\begin{array}{l}9 \\
19 \\
\end{array}$ & $\begin{array}{l}66.7 \\
100.0 \\
\end{array}$ & 0.026 & Sig \\
\hline $\begin{array}{ll}\text { Stage } & \text { IIE } \\
& \text { IVE }\end{array}$ & $\begin{array}{l}22 \\
8\end{array}$ & $\begin{array}{l}100.0 \\
37.5\end{array}$ & $<0.001$ & Sig & $\begin{array}{l}22 \\
6\end{array}$ & $\begin{array}{l}100.0 \\
50.0\end{array}$ & 0.006 & Sig \\
\hline $\begin{array}{r}\text { Response to CT } \\
\text { YES } \\
\text { NO } \\
\end{array}$ & $\begin{array}{l}25 \\
5 \\
\end{array}$ & $\begin{array}{l}100.0 \\
0.0\end{array}$ & $<0.001$ & Sig & $\begin{array}{l}25 \\
3 \\
\end{array}$ & $\begin{array}{l}100.0 \\
0.0\end{array}$ & $<0.001$ & Sig \\
\hline $\begin{array}{c}\text { CT complication } \\
\text { YES } \\
\text { NO }\end{array}$ & $\begin{array}{l}2 \\
28 \\
\end{array}$ & $\begin{array}{l}0.0 \\
89.3 \\
\end{array}$ & 0.023 & Sig & - & - & - & - \\
\hline $\begin{aligned} & \text { Ki67 } \text { Low value } \\
& \text { High value } \\
&\end{aligned}$ & $\begin{array}{l}13 \\
17 \\
\end{array}$ & $\begin{array}{l}100.0 \\
70.6\end{array}$ & 0.04 & Sig & $\begin{array}{l}13 \\
13 \\
\end{array}$ & $\begin{array}{l}100.0 \\
80.0\end{array}$ & 0.226 & NS \\
\hline
\end{tabular}

Table 4: Comparison of clinicopathological factors with various study group.

\begin{tabular}{|l|l|l|l|}
\hline Study group & AGE & SITE & Histo type \\
\hline $\begin{array}{l}\text { RanjanBandyopadhyay et } \\
\text { al 2011 }\end{array}$ & $1-8$ yrs (6 cases) & Small bowel (50\%) & Burkitt (66\%) \\
\hline Morsi et al 2005 & $1-15$ yrs (43 cases) & Small bowel (35\%) & Burkitt (56\%) \\
\hline Khurshed et al 2007 & $1-19$ yrs (60 cases) & Colon (85\%) & Burkitt (47\%) \\
\hline Bethel CA et al 1997 & $1-17$ yrs (55 cases) & $\begin{array}{l}\text { Small intestine } \\
(22 \%)\end{array}$ & Burkitt (38\%) \\
\hline Current study & $1-12$ yrs (30 cases) & $\begin{array}{l}\text { Small intestine } \\
(66 \%)\end{array}$ & Burkitt (33\%) \\
\hline
\end{tabular}

